Case Report

\title{
A Leydig Cell Tumour in a Cat: Histological and Immunohistochemical Findings
}

\author{
Pietro Asproni, Francesca Millanta, Davide Lorenzi, and Alessandro Poli \\ Department of Veterinary Sciences, University of Pisa, Viale delle Piagge, 2, 56124 Pisa, Italy \\ Correspondence should be addressed to Pietro Asproni; pietro.asproni@for.unipi.it
}

Received 25 February 2013; Accepted 24 March 2013

Academic Editors: C. Hyun, A. F. Koutinas, and R. M. Santos

Copyright (C) 2013 Pietro Asproni et al. This is an open access article distributed under the Creative Commons Attribution License, which permits unrestricted use, distribution, and reproduction in any medium, provided the original work is properly cited.

\begin{abstract}
A 13-year-old intact male cat was submitted to castration after the finding of the enlargement of the right testis during the clinical visit. Macroscopically, a nodule of $2 \mathrm{~cm}$ of diameter was observed on the cut surface of the enlarged testis. Histologically, the nodule was composed by polyhedral to elongated cells with a large, eosinophilic, and vacuolated cytoplasm and small, round, and dark nuclei. These cells were arranged in acinar structures and solid sheets. The tumour was diagnosed as a Leydig cell tumour. Immunohistochemical analysis revealed that neoplastic cells were vimentin, calretinin, and melan-A positive, whereas a lack of immunoreactivity to cytokeratins confirmed the diagnosis. To our knowledge, this is the first description of a feline Leydig cells tumour without any concurrent testicular neoplasm or in a nonretained testis.
\end{abstract}

\section{Introduction}

Leydig cell tumours are neoplasms originating from the interstitial Leydig cells of the testis. These tumours are common in dogs and more rarely reported in other species [1]. In cats, few cases of testicular tumors have been, up now, described $[2,3]$ including some Leydig cell tumours located in retained testis, in castrated cats, or with a concurrent testicular neoplasm [4-7]. Here, we describe for the first time a case of feline leydigioma occurring in a noncastrated cat and without testicular retention.

\section{Case Presentation}

At the clinical exam, a 13-year-old intact European shorthair male cat showed the increase in volume and firmness of the right testis, while the left one was atrophic. Both were normally located into the scrotum. Ultrasonographic investigations allowed to identify an hypoechogenic nodule of $2 \mathrm{~cm}$ of diameter in the enlarged testis. The cat did not present behavioral alterations as aggressiveness, feminization, or inappropriate urination. According to the owner's will, the cat was submitted to surgery to remove both the gonads.

On gross evaluation, the mass of the right testis was yellow to brown-colored and firm and elastic at the palpation. The neoplasm was well circumscribed and clearly demarcated from the healthy testis. Tissue samples were fixed in $10 \%$ neutral buffered formalin and processed by routine methods for histological investigation. Four $\mu \mathrm{m}$ thick sections were cut and stained with hematoxylin and eosin for microscopic examination. Further tissue sections were prepared for immunohistochemical staining. Immunohistochemistry was performed with the biotin-streptavidin-peroxidase method with primary antibodies against human pan-cytokeratins $(\mathrm{CK})$, vimentin, melan- $\mathrm{A}$, and calretinin. The chromogen was 3,3'-diaminobenzidine (ImmPACT DAB, Vector Laboratories, Burlingame, CA, USA) for all the antibodies (10 min at room temperature). Feline skin (for CK and vimentin), adrenal gland (for calretinin), and amelanotic melanoma (for melan-A) samples were used as positive control tissues. As negative control, the primary antibodies were replaced with nonimmune rabbit serum or replacing the primary monoclonal antibodies with a murine subclass matched unrelated antibodies. Immunohistochemical protocols and results are described in Table 1.

Histological examination revealed the presence of solid sheets and acinar structures composed by polyhedral to elongated cells with a large, eosinophilic, and vacuolated cytoplasm and small, dark, and round nuclei (Figure 1(a)). These vacuoles were of different sizes and optically empty. 


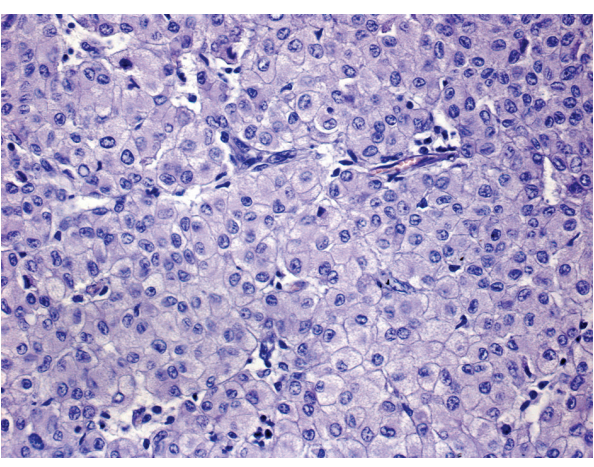

(a)

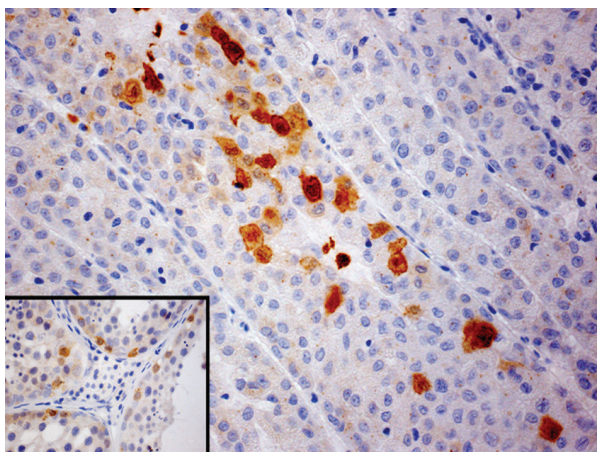

(c)

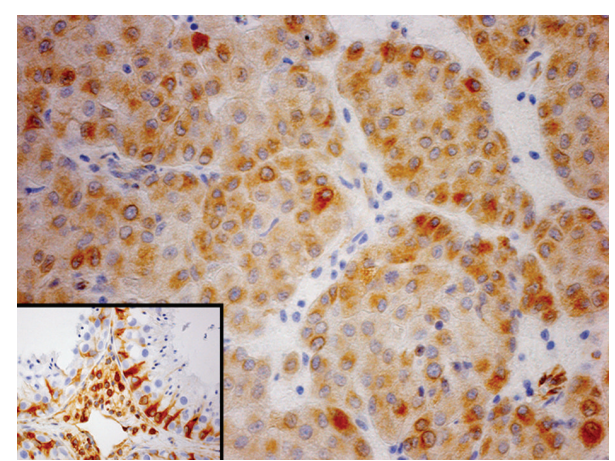

(b)

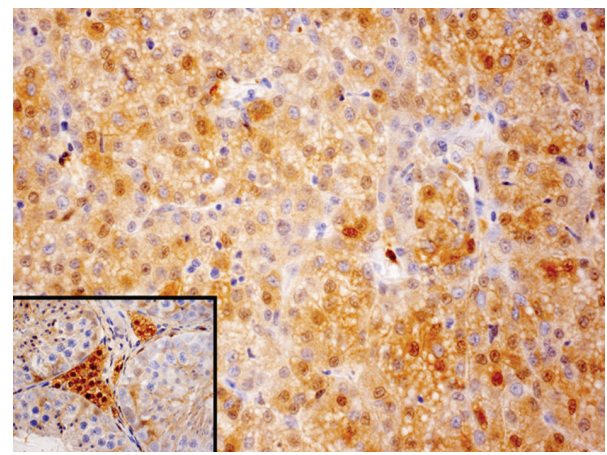

(d)

FIGURE 1: Cat; testis; Leydig cell tumour. (a) Neoplastic polyhedral Leydig cells with a large, eosinophilic, and vacuolated cytoplasm and a small and dark nuclei. These cells are arranged in solid sheets surrounded by a fine connective stroma in which a vascular structure can be observed. Hematoxylin and Eosin stain, $\times 40$. (b) Diffuse cytoplasmic immunoreactivity of neoplastic cells to vimentin. Biotin-streptavidinperoxidase method and hematoxylin counterstain. $\times 40$. (c) Weak immunolabeling of tumour cells to calretinin antibody with some foci of strong intensity. Biotin-streptavidin-peroxidase method and hematoxylin counterstain. $\times 40$. (d) Diffuse immunolabeling of neoplastic cells to melan-A antibody. Biotin-streptavidin-peroxidase method and hematoxylin counterstain. $\times 40$. Inserts: immunolabeling in normal testicular tissue to the respective markers.

TABLE 1: Primary antibodies for immunohistochemistry and reactivity of feline Leydig cell tumour.

\begin{tabular}{|c|c|c|c|c|c|c|}
\hline Antibody & Type (clone) & Company & Dilution & Incubation & Antigen retrieval $^{\mathrm{a}}$ & $\begin{array}{l}\text { Immunoreactivity of } \\
\text { neoplastic cells }\end{array}$ \\
\hline Cytokeratin & MM (AE1/AE3) & Santa Cruz & $1: 100$ & 1 hour & MW & Negative \\
\hline Vimentin & MM (V9) & Novocastra & $1: 100$ & 1 hour & MW & Positive \\
\hline Melan-A & MM (A103) & Ventana & prediluted & 1 hour & MW & Positive \\
\hline Calretinin & $\mathrm{RP}$ & Cell Marque & prediluted & 1 hour & MW & Positive \\
\hline
\end{tabular}

MM: mouse monoclonal; RP: rabbit polyclonal; MW: microwave.

${ }^{\mathrm{a}}$ Antigen retrieval: microwaved in $0.01 \mathrm{M}$ citrate buffer ( $\mathrm{pH} 6.0$ ) at $650 \mathrm{~W}$ for 4 minutes and at $350 \mathrm{~W}$ for 15 minutes.

Neoplastic cell sheets and acinar structures were surrounded by a fine supporting connective stroma in which vascular formations were often present. In some parts of the tumour, small hemorrhagic foci were observed. Mitotic figures were very rare and bipolar. Due to microscopic findings, the neoformation was diagnosed as a Leydig cell tumour.

Immunohistochemistry showed a cytoplasmic positivity of neoplastic cells to vimentin (Figure 1(b)) and the lack of immunoreactivity to CK. These cells showed a weak and focal calretinin expression (Figure 1(c)) and strong melanA cytoplasmic positivity (Figure 1(d)). These immunohistochemical findings allowed to confirm the diagnosis of Leydig cells tumour.

\section{Discussion}

Leydig cell tumours are common in dogs [1], whereas in cats they are only rarely described. These reports concern interstitial tumours occurred in ectopic testes or in cats previously submitted to castration [4-7]. In one of these cases, the Leydig cells tumour was associated with a Sertoli cell tumour [5]. Considering these reports, the tumour here described is the first case of Leydig cell tumour affecting a normally located testis and without any concurrent neoplasm.

The immunohistochemical panel allowed to better characterize the nodule. Vimentin immunoreactivity of neoplastic cells and the lack of CK expression has been previously 
described by Miller and colleagues in a interstitial tumour associated with a Sertoli cell tumour in a castrated cat [5]. Calretinin has been reported to be a useful immunohistochemical marker for normal and neoplastic human Leydig cells $[8,9]$. In the case here described, calretinin was expressed mainly with a weak intensity with some foci of strong expression, as yet reported by Miller and colleagues [5].

Melan-A expression in Leydig cells has been reported in human [9] and canine tumours [10]. Melan-A belongs to a group of melanocytic differentiation antigens and its clone A103 is used to detect steroid hormones producing cells, even Leydig cells. For this reason, the research of melan-A expression by immunohistochemistry may help to recognize normal and neoplastic Leydig cells. Furthermore, melan-A immunoreactivity could suggest the androgens production by this tumour that can lead to alterations in the behavior of the affected cat, with episodes of aggressiveness or inappropriate urination [5-7]. The cat bearing the tumour here described did not show these signs, but the previous articles reported this possibility.

In conclusion, this report describes a rare case of feline genital system tumour with a novel clinical onset and with a detailed histological and immunohistochemical characterization. On the basis of our findings, Leydig cell tumor may be included in the differential diagnosis of feline testicular pathologies.

\section{Conflict of Interests}

The authors declare that there is no conflict of interests.

\section{References}

[1] N. J. MacLachlan and P. C. Kennedy, "Tumors of the genital systems," in Tumors in Domestic Animals, D. J. Meuten, Ed., pp. 547-567, Iowa State Press, Ames, Iowa, USA, 4th edition, 2002.

[2] C. Benazzi, G. Sarli, and B. Brunetti, "Sertoli cell tumour in a cat," Journal of Veterinary Medicine A, vol. 51, no. 3, pp. 124-126, 2004.

[3] N. Miyoshi, N. Yasuda, Y. Kamimura, M. Shinozaki, and T. Shimizu, "Teratoma in a feline unilateral cryptorchid testis," Veterinary Pathology, vol. 38, no. 6, pp. 729-730, 2001.

[4] A. L. Doxsee, J. A. Yager, S. J. Best, and R. A. Foster, "Extratesticular interstitial and Sertoli cell tumors in previously neutered dogs and cats: a report of 17 cases," The Canadian Veterinary Journal, vol. 47, no. 8, pp. 763-766, 2006.

[5] M. A. Miller, S. E. Hartnett, and J. A. Ramos-Vara, "Interstitial cell tumor and Sertoli cell tumor in the testis of a cat," Veterinary Pathology, vol. 44, no. 3, pp. 394-397, 2007.

[6] D. K. Rosen and J. L. Carpenter, "Functional ectopic interstitial cell tumor in a castrated male cat," Journal of the American Veterinary Medical Association, vol. 202, no. 11, pp. 1865-1866, 1993.

[7] A. R. Tucker and J. R. Smith, "Prostatic squamous metaplasia in a cat with interstitial cell neoplasia in a retained testis," Veterinary Pathology, vol. 45, no. 6, pp. 905-909, 2008.

[8] D. Augusto, E. Leteurtre, A. De La Taille, B. Gosselin, and X. Leroy, "Calretinin: a valuable marker of normal and neoplastic
Leydig cells of the testis," Applied Immunohistochemistry and Molecular Morphology, vol. 10, no. 2, pp. 159-162, 2002.

[9] R. E. Emerson and T. M. Ulbright, "The use of immunohistochemistry in the differential diagnosis of tumors of the testis and paratestis," Seminars in Diagnostic Pathology, vol. 22, no. 1, pp. 33-50, 2005.

[10] J. A. Ramos-Vara, M. E. Beissenherz, M. A. Miller et al., "Immunoreactivity of A103, an antibody to Melan A, in canine steroid-producing tissues and their tumors," Journal of Veterinary Diagnostic Investigation, vol. 13, no. 4, pp. 328-332, 2001. 

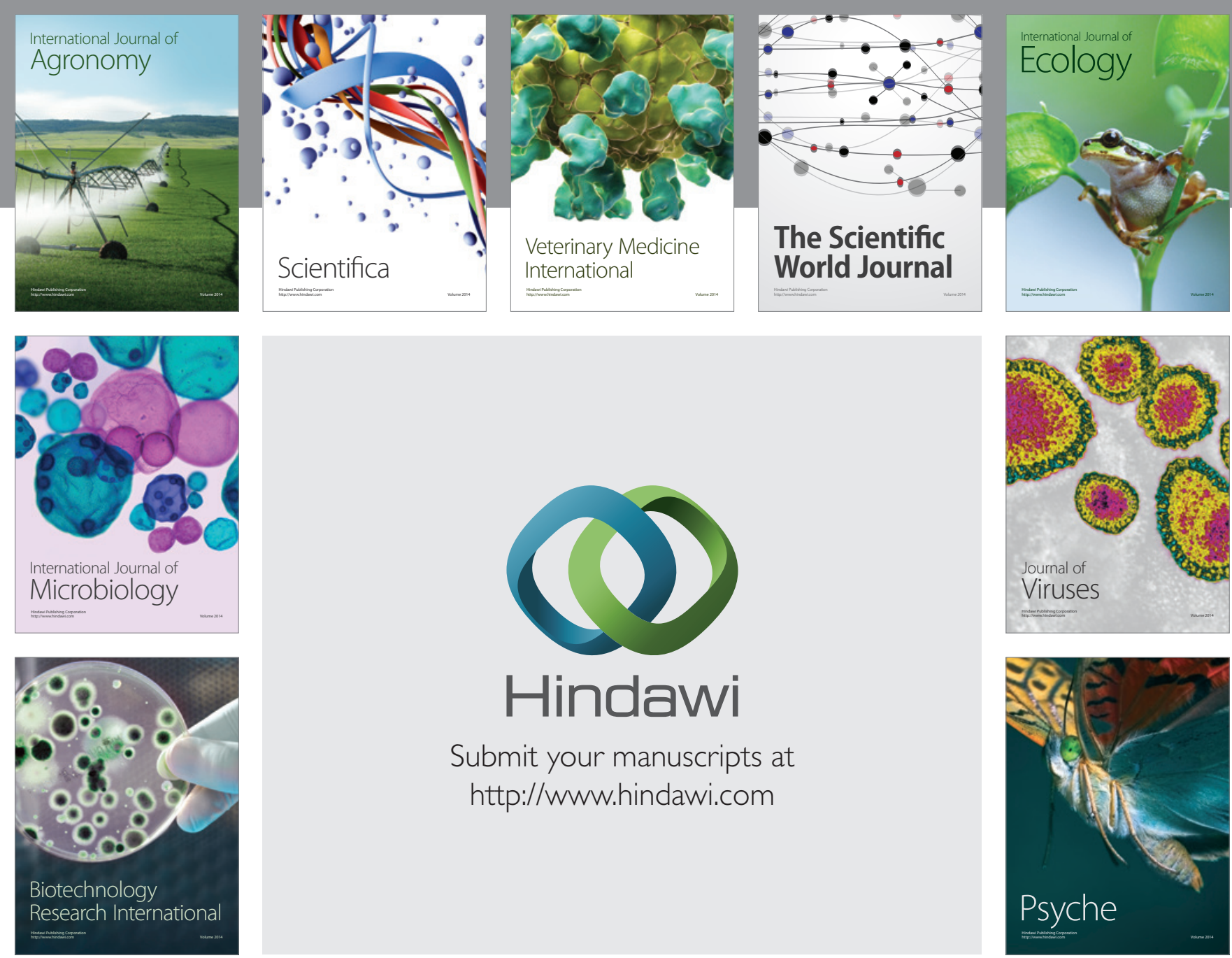

Submit your manuscripts at http://www.hindawi.com
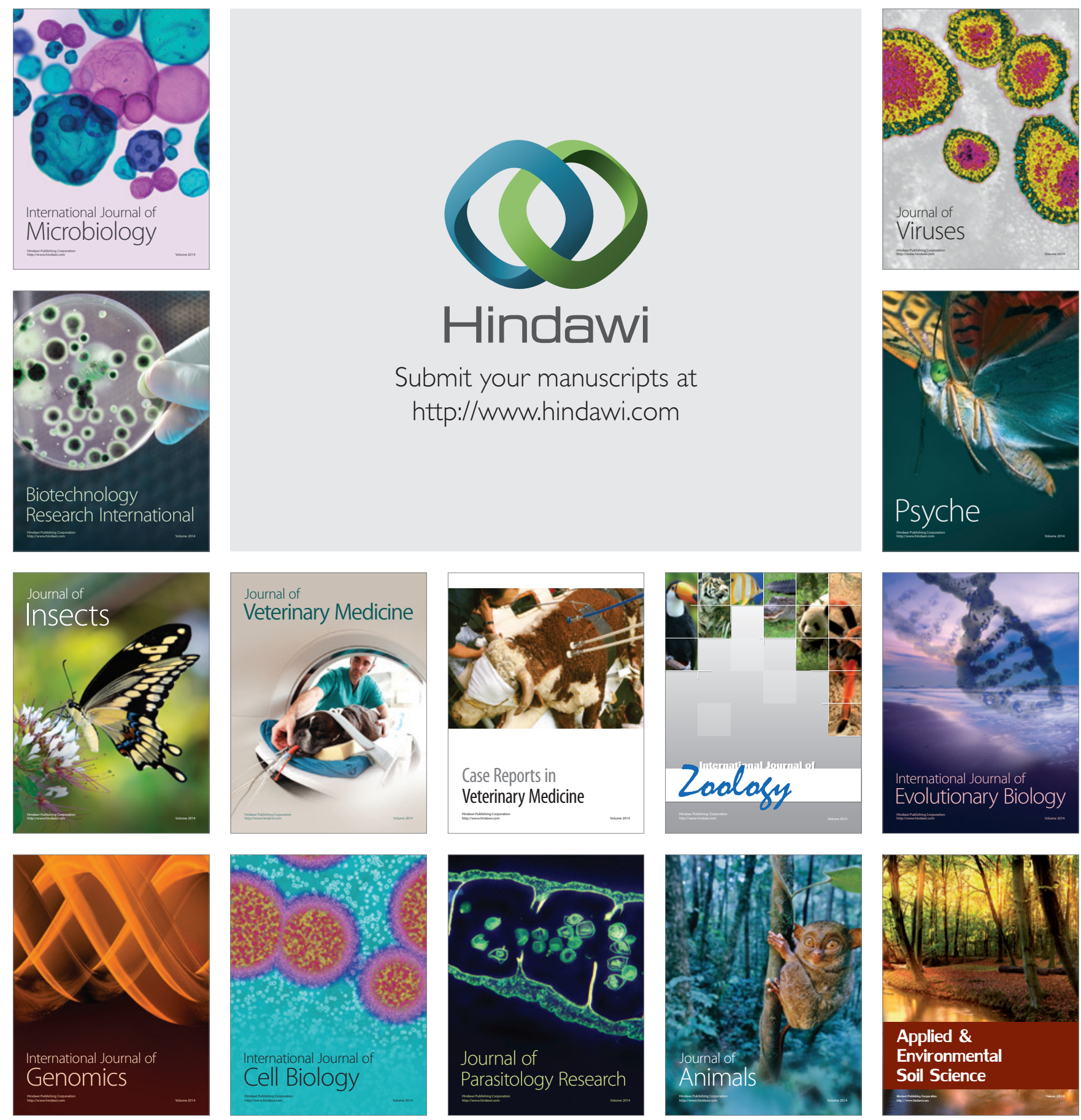